J. Dairy Sci. 92:3939-3950

doi:10.3168/jds.2008-1992

(c) American Dairy Science Association, 2009.

\title{
In vitro digestibility of individual amino acids in rumen-undegraded protein: The modified three-step procedure and the immobilized digestive enzyme assay ${ }^{1}$
}

\author{
S. E. Boucher, ${ }^{* 2}$ S. Calsamiglia,† C. M. Parsons,‡ M. D. Stern,§ M. Ruiz Moreno,§ M. Vázquez-Añón,\# \\ and C. G. Schwab*3 \\ ${ }^{*}$ Department of Biological Sciences, University of New Hampshire, Durham 03824 \\ †Facultad de Veterinaria, Universitat Autònoma de Barcelona, 08193 Bellaterra, Spain \\ ‡Department of Animal Sciences, University of Illinois, Champaign 61801 \\ $\S$ Department of Animal Science, University of Minnesota, St. Paul 55108 \\ \#Novus International Inc., St. Louis, MO 63147
}

\begin{abstract}
Three soybean meal, 3 SoyPlus (West Central Cooperative, Ralston, IA), 5 distillers dried grains with solubles, and 5 fish meal samples were used to evaluate the modified 3-step in vitro procedure (TSP) and the in vitro immobilized digestive enzyme assay (IDEA; Novus International Inc., St. Louis, MO) for estimating digestibility of AA in rumen-undegraded protein (RUP-AA). In a previous experiment, each sample was ruminally incubated in situ for $16 \mathrm{~h}$, and in vivo digestibility of AA in the intact samples and in the rumen-undegraded residues (RUR) was obtained for all samples using the precision-fed cecectomized rooster assay. For the modified TSP, $5 \mathrm{~g}$ of RUR was weighed into polyester bags, which were then heat-sealed and placed into Daisy ${ }^{\text {II }}$ incubator bottles. Samples were incubated in a pepsin $/ \mathrm{HCl}$ solution followed by incubation in a pancreatin solution. After this incubation, residues remaining in the bags were analyzed for AA, and digestibility of RUP-AA was calculated based on disappearance from the bags. In vitro RUP-AA digestibility estimates obtained with this procedure were highly correlated to in vivo estimates. Corresponding intact feeds were also analyzed via the pepsin/pancreatin steps of the modified TSP. In vitro estimates of AA digestibility of the feeds were highly correlated to in vivo RUP-AA digestibility, which suggests that the feeds may not need to be ruminally incubated before determining RUP-AA digestibility in vitro. The RUR
\end{abstract}

\footnotetext{
Received December 22, 2008.

Accepted March 31, 2009.

${ }^{1}$ This is Scientific Contribution number 2389 from the New Hampshire Agricultural Experiment Station contributing to Regional Research Project NC-1009.

${ }^{2}$ Current address: William H. Miner Agricultural Research Institute, Chazy, NY 12921.

${ }^{3}$ Corresponding author: charles.schwab@unh.edu
}

were also analyzed via the IDEA kits. The IDEA values of the RUR were good predictors of RUP-AA digestibility in soybean meal, SoyPlus, and distillers dried grains with solubles, but the IDEA values were not as good predictors of RUP-AA digestibility in fish meal. However, the IDEA values of intact feed samples were also determined and were highly correlated to in vivo RUP-AA digestibility for all feed types, suggesting that the IDEA value of intact feeds may be a better predictor of RUP-AA digestibility than the IDEA value of the RUR. In conclusion, the modified TSP and IDEA kits are good approaches for estimating RUP-AA digestibility in soybean meal products, distillers dried grains with solubles, and fish meal samples.

Key words: amino acid digestibility, modified threestep procedure, immobilized digestive enzyme assay

\section{INTRODUCTION}

The current dairy NRC (2001) model recognizes that intestinal digestibility of RUP varies among and within feedstuffs, but the model does not recognize differences in digestibility of individual AA in the RUP (RUPAA) fraction of feeds. Currently, data regarding RUPAA digestibility for individual feed ingredients are limited due in large part to the difficulty in obtaining these estimates in ruminant animals. In vivo models to determine digestibility of RUP-AA have been evaluated (Titgemeyer et al., 1990), but an in vitro procedure to estimate RUP-AA digestibility would allow for more routine analysis of feeds for this parameter.

The most common in vitro procedure used to estimate RUP digestibility is the 3-step procedure (TSP) of Calsamiglia and Stern (1995); however, this procedure is not used to estimate RUP-AA digestibility. The 3 steps of the procedure are 1) ruminal incubation, 2) pepsin digestion, and 3) pancreatin digestion. The pepsin and pancreatin digestions of the rumen-undegraded residues 
(RUR) are performed in centrifuge tubes, and at the end of the procedure, undigested protein is precipitated with TCA. Use of TCA prohibits AA quantification of the postdigestion product via cation-exchange HPLC, which is the most common method for AA analysis. Recently, Gargallo et al. (2006) modified the TSP so that digestibility of RUP-AA could be determined. With the modifications, the RUR are incubated with digestive enzymes in polyester bags, which allows for collection of a final undigested residue. This final residue can be analyzed for AA content, and intestinal RUP-AA digestibility can be calculated as percentage disappearance of AA from the bags. Gargallo et al. (2006) observed a high correlation between RUP digestibility determined with the original and modified TSP; however, they did not validate in vitro RUP-AA digestibility measurements with in vivo data.

The immobilized digestive enzyme assay (IDEA) is another in vitro assay that can be used to estimate digestibility of protein and AA in feeds (Church et al., 1984; Schasteen et al., 2007). The assay was developed to determine digestibility of protein in human foodstuffs, originally required $2.5 \mathrm{~d}$ to complete, and employed a complex system of proteases immobilized to glass beads (Church et al., 1984). Schasteen et al. (2007) developed IDEA kits (Novus International Inc., St. Charles, MO) to provide a more rapid prediction of protein and AA digestibility than the original IDEA procedure would allow. The IDEA kits have been developed for a variety of protein supplements (Novus International, 2008); however, none of the kits have been evaluated to estimate intestinal RUP-AA digestibility using ruminally undegraded feed residues.

The objective of this experiment was to determine if the modified TSP and the IDEA kit assays can be utilized to accurately predict digestibility of RUP-AA in soybean meal (SBM), SoyPlus (SP; West Central Cooperative, Ralston, IA), distillers dried grains with solubles (DDGS), and fish meal (FM). Because Lys digestibility is highly variable, and Lys is a limiting AA for milk and milk protein production (NRC, 2001), in vitro Lys digestibility estimates are emphasized. In addition, samples were analyzed via the original TSP to compare RUP digestibility estimates between the original and modified procedures.

\section{MATERIALS AND METHODS}

Samples evaluated in this experiment were described by Boucher et al. (2009a,b). The samples evaluated were 3 samples of SBM, 3 samples of SP, 5 samples of DDGS, and 5 samples of FM before and after a 16-h ruminal incubation. One each of the SBM, SP, and DDGS samples were heated to reduce Lys digestibility.
In vivo Lys digestibility in the intact samples and Lys digestibility in the RUR (represents RUP-Lys) was determined using the precision-fed cecectomized rooster assay. Details of the heating procedures, the ruminal incubation procedure, and the chemical composition of the intact feed and RUR samples were also described (Boucher et al., 2009a,b). All intact feed and RUR samples were ground to pass a 1-mm screen using a Wiley mill (Thomas Scientific, Swedesboro, NJ) before analysis.

\section{Original TSP}

The RUR samples were analyzed using the original TSP (Calsamiglia and Stern, 1995) at the University of Minnesota (St. Paul). Briefly, the samples were incubated in a pepsin/ $\mathrm{HCl}$ solution for $1 \mathrm{~h}$, followed by incubation in a pancreatin $/ \mathrm{KH}_{2} \mathrm{PO}_{4}$ solution for $24 \mathrm{~h}$. After the pancreatin incubation, TCA was added to the tubes to precipitate undigested proteins. Samples were then centrifuged (Avanti J-25 I, Beckman Instruments Inc., Palo Alto, CA), and the supernatant was analyzed for N content by the Kjeldahl method (AOAC, 1980). Digestibility of RUP was calculated as TCA-soluble N divided by the amount of sample N.

\section{Modified TSP}

The RUR and intact feed samples were also analyzed using the pepsin and pancreatin digestion steps of the modified TSP described by Gargallo et al. (2006). For this procedure, 2 different types of bags were evaluated: polyester bags with a pore size of $50 \mu \mathrm{m}$ (Ankom R510, Ankom Technology, Macedon, NY) and bags with a pore size of $25 \mu \mathrm{m}$ (Ankom F57, Ankom Technology). Briefly, $5 \mathrm{~g}$ of sample was weighed into the Ankom R510 bags, and $1 \mathrm{~g}$ of sample was weighed into the Ankom F57 bags in duplicate. The samples were then incubated in a pepsin/ $\mathrm{HCl}$ solution for $1 \mathrm{~h}$ in a Daisy ${ }^{\mathrm{II}}$ incubator (Ankom Technology), followed by incubation in a pancreatin $/ \mathrm{KH}_{2} \mathrm{PO}_{4}$ solution for $24 \mathrm{~h}$. The maximum number of bags in each bottle was 30. After 24 $\mathrm{h}$, the liquid was drained from the bottles, and bags were again rinsed until the runoff was clear. Bags were allowed to drain and were dried in a forced hot air oven at $55^{\circ} \mathrm{C}$ for $48 \mathrm{~h}$. The dry weights of the samples and bags were recorded, and bags were opened and pooled by sample for AA analysis. A portion of residue remaining after in vitro incubation was analyzed for $\mathrm{CP}$ via combustion analyzer (AOAC, 2000; method 990.03; Experimental Station Chemical Laboratories, University of Missouri-Columbia, Columbia), and AA content via cation-exchange chromatography (cIEC-HPLC) coupled with postcolumn ninhydrin derivatization and 
Table 1. In vitro digestibility (\%) of amino acids and CP in SoyPlus (SP; West Central Cooperative, Ralston, IA) and soybean meal (SBM) samples before (intact feed) and after (rumen residue) a 16-h ruminal in situ incubation determined via the modified 3-step procedure

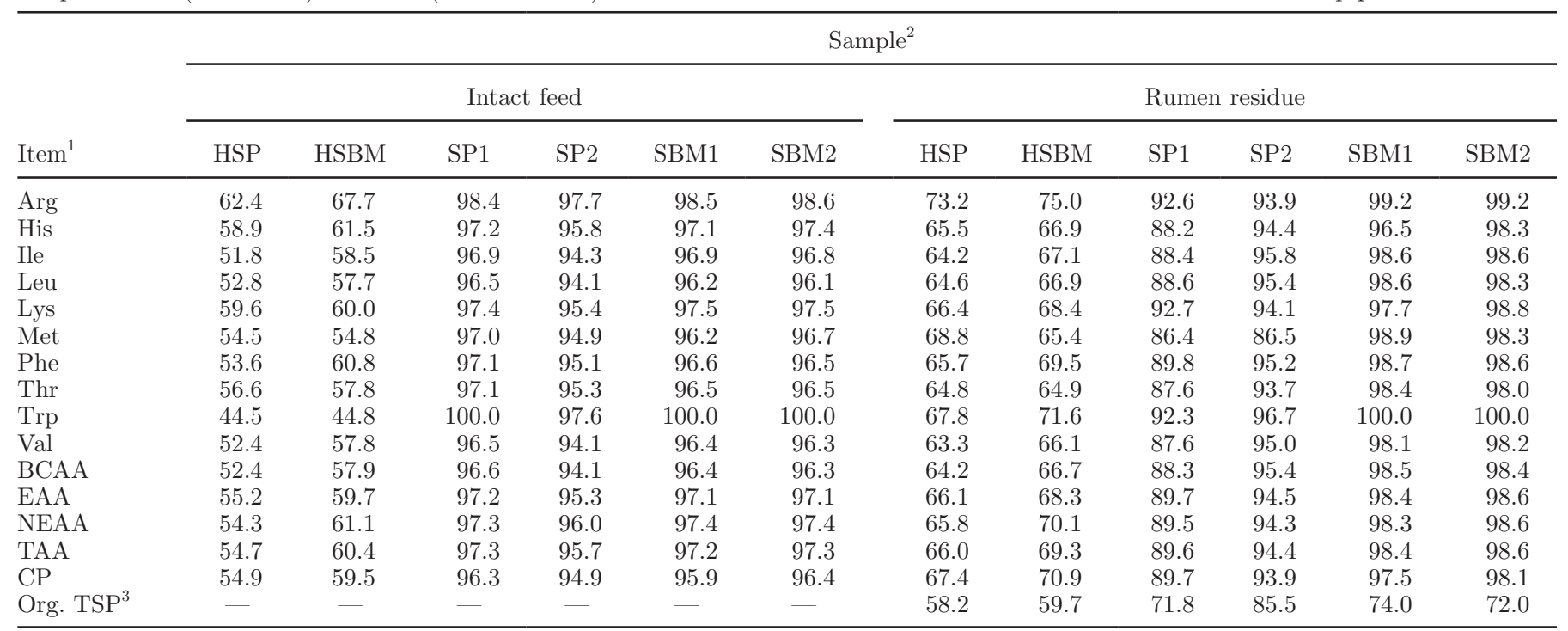

${ }^{1} \mathrm{BCAA}=$ branched chained $\mathrm{AA} ; \mathrm{EAA}=$ essential AA; NEAA = nonessential AA; TAA = total AA.

${ }^{2} \mathrm{H}$ indicates the sample was heated at $150^{\circ} \mathrm{C}$ for $90 \mathrm{~min}$; numbers following samples indicate these samples are from different sources or batches. Heated samples were independent samples and do not correspond to another sample.

${ }^{3}$ Rumen-undegradable protein digestibility determined via the original 3-step procedure of Calsamiglia and Stern (1995).

quantitation (AOAC, 2000; method 982.30; Experimental Station Chemical Laboratories, University of Missouri-Columbia). The CP and AA contents of the feeds and rumen residues were previously determined (Boucher et al., 2009a,b; Experimental Station Chemical Laboratories, University of Missouri-Columbia). Pepsin-pancreatin digestion of CP and AA in the RUR and intact feeds was calculated as follows:

$$
\begin{gathered}
\% \text { digested }=[(\text { amount of AA in, } \mathrm{g},- \text { amount } \\
\text { of AA out, g) } / \text { amount of AA in, g }] \times 100 \text {. }
\end{gathered}
$$

\section{IDEA}

All intact feed and RUR samples were analyzed using IDEA kit assays supplied by Novus International Inc. The IDEA analysis was performed by researchers from the University of New Hampshire in collaboration with research technicians at the Novus research laboratory. Each kit included the procedure, a standard, and digestor tubes that contained digestive enzymes immobilized to succinamidopropyl-glass beads stored in 0.25 $\mathrm{mL}$ of a $50 \mathrm{~m} M$ phosphate buffer. The 3 basic steps for each kit were 1) solubilization, 2) digestion, and 3) protein digestion quantification via $o$-phthaldialdehyde (OPA) analysis. The solubilization and digestion procedures varied according to sample type, but the protein digestion quantification procedure was similar across feed types. Each sample was digested in duplicate.

$\boldsymbol{S B M}$ and $\boldsymbol{S P}$. For SBM and SP intact feed and RUR samples, $0.64 \mathrm{~g}$ of each sample were weighed into 50-mL Erlenmeyer flasks. Forty milliliters of a potassium phosphate-sodium azide solution was then added to each flask. Samples were mixed at $700 \mathrm{rpm}$ using a magnetic stir bar and plate for $4 \mathrm{~h}$ at room temperature $\left(22^{\circ} \mathrm{C}\right)$. After $4 \mathrm{~h}, \mathrm{pH}$ was adjusted to 7.5 with a $12.5 \mathrm{M}$ $\mathrm{NaOH}$ solution. While the samples were stirring, $1 \mathrm{~mL}$ of the solution was transferred to a centrifuge tube for the initial OPA analysis, and $0.25 \mathrm{~mL}$ of the solubilized sample was transferred to digestor tubes. The digestor tubes were then mixed on an end-to-end rotator in an incubator at $37^{\circ} \mathrm{C}$ for $18 \mathrm{~h}$. After $18 \mathrm{~h}$, samples were removed from the incubator, and samples were allowed to settle by gravity. The supernatant was transferred to a centrifuge tube for the final OPA analysis.

$\boldsymbol{D D} \boldsymbol{G} \boldsymbol{S}$. For the DDGS intact feed and RUR samples, $1.92 \mathrm{~g}$ of sample was weighed into 50-mL Erlenmeyer flasks and $40 \mathrm{~mL}$ of a disodium phosphate-sodium azide solution ( $\mathrm{pH} 7.7$ ) was added to the flasks. Samples were mixed using a magnetic stir bar and plate for 60 min at room temperature. After this step, $0.25 \mathrm{~mL}$ of the solution was transferred to a DDGS digestor tube and samples were mixed on an end-to-end rotator in an incubator at $37^{\circ} \mathrm{C}$ for $18 \mathrm{~h}$. After $18 \mathrm{~h}$, samples were removed from the incubator, and samples were allowed to 
Table 2. In vitro digestibility (\%) of amino acids and CP in samples of distillers dried grains with solubles (DDGS) before (intact feed) and after (rumen residue) a 16-h ruminal in situ incubation determined via the modified 3-step procedure

\begin{tabular}{|c|c|c|c|c|c|c|c|c|c|c|}
\hline Item $^{1}$ & \multicolumn{10}{|c|}{ Sample $^{2}$} \\
\hline $\operatorname{Arg}$ & 19.0 & 89.7 & 91.1 & 86.2 & 89.6 & 39.5 & 89.9 & 95.6 & 92.9 & 93.3 \\
\hline His & 25.8 & 87.9 & 88.0 & 82.6 & 87.0 & 45.5 & 89.8 & 95.0 & 91.7 & 92.1 \\
\hline Ile & 24.0 & 86.1 & 86.7 & 80.2 & 87.0 & 50.8 & 91.5 & 96.4 & 93.4 & 93.8 \\
\hline Met & 21.9 & 88.0 & 88.4 & 82.9 & 88.8 & 57.2 & 92.6 & 97.0 & 94.7 & 95.4 \\
\hline Phe & 28.9 & 88.3 & 88.0 & 83.0 & 88.2 & 54.3 & 92.7 & 96.8 & 94.3 & 94.7 \\
\hline Thr & 22.9 & 85.3 & 86.7 & 80.8 & 85.3 & 41.1 & 85.8 & 92.9 & 89.9 & 90.4 \\
\hline $\operatorname{Trp}^{3}$ & - & 100.0 & 100.0 & 100.0 & 100.0 & - & 100.0 & 100.0 & 100.0 & 100.0 \\
\hline Val & 21.3 & 85.4 & 85.4 & 78.6 & 85.0 & 46.5 & 90.2 & 95.7 & 92.1 & 92.2 \\
\hline BCAA & 26.6 & 87.3 & 86.3 & 81.5 & 87.3 & 53.9 & 93.0 & 96.7 & 94.2 & 94.6 \\
\hline EAA & 23.9 & 87.5 & 87.5 & 82.1 & 87.5 & 50.1 & 91.4 & 95.9 & 93.3 & 93.8 \\
\hline
\end{tabular}

${ }^{1} \mathrm{BCAA}=$ branched chained $\mathrm{AA} ; \mathrm{EAA}=$ essential AA; NEAA = nonessential AA; TAA = total AA.

${ }^{2} \mathrm{H}$ indicates the sample was heated at $140^{\circ} \mathrm{C}$ for $60 \mathrm{~min}$; numbers following samples indicate these samples are from different sources or batches. Heated samples were independent samples and do not correspond to another sample.

${ }^{3}$ Trp digestibility of all DDGS samples is $100 \%$ because the quantity of Trp in the undegraded, undigested residue obtained from the modified 3 -step procedure was less than $0.04 \%$ of DM, which is below the threshold for accurate quantification of Trp content with the method used.

${ }^{4}$ Rumen-undegradable protein digestibility determined via the original 3-step procedure of Calsamiglia and Stern (1995).

settle by gravity. The supernatant was then transferred to an empty centrifuge tube for OPA analysis.

$\boldsymbol{F M}$. For the FM intact feed and RUR samples, the amount of sample weighed into the flasks varied so that each flask contained $160 \mathrm{mg}$ of CP. A $0.04 \mathrm{M} \mathrm{HCl} \mathrm{solu-}$ tion was added to the flasks so that the sample concentration was $8 \mathrm{mg} / \mathrm{mL}$ of solution. Samples were stirred for $15 \mathrm{~min}$, and $\mathrm{pH}$ was adjusted to 2 . One milliliter of the solubilized sample was transferred to a centrifuge tube for the initial OPA analysis, and $2.5 \mathrm{~mL}$ of solubilized sample was added to the digestor tubes. Tubes were mixed for $2 \mathrm{~h}$ at $37^{\circ} \mathrm{C}$, after which the sample was allowed to settle by gravity, and the supernatant was transferred to an empty centrifuge tube for the final OPA analysis.

IDEA Protein Digestion Quantification. Protein digestion via the IDEA kits was quantified by the reaction of $\alpha$-amino groups with OPA (Schasteen et al., 2007). Briefly, $1 \mathrm{~mL}$ of the OPA solution was added to disposable cuvettes. The solubilized (initial) and digested (final) samples were mixed, and $10 \mu \mathrm{L}$ of the initial and final samples were added to the cuvettes filled with the OPA reagent. Absorbance was read at $340 \mathrm{~nm}\left(\mathbf{A}_{\mathbf{3 4 0}}\right)$ on a spectrophotometer (Varian Associates, Sunnyvale, CA). Absorbance of the initial and final samples was used to calculate IDEA values for SBM, SP, and FM samples. For the DDGS samples, the IDEA values were calculated solely from the absorbance of the final sample because no initial sample was collected.

\section{IDEA Calculations}

The IDEA values were calculated as follows:

$\mathrm{SBM}$ and $\mathrm{SP}$ : IDEA value $=\mathrm{A}_{340}$ final

- $\left(0.5 \times \mathrm{A}_{340} \mathrm{initial}\right) /$ percentage protein;

DDGS: IDEA value $=\mathrm{A}_{340}$ final $/$ percentage protein;

FM: IDEA value $=\mathrm{A}_{340}$ final $-\left(0.75 \times \mathrm{A}_{340}\right.$ initial $) /$

percentage protein.

A standardization factor was also calculated:

Standardization factor $=$ Novus predetermined

IDEA value for standard/measured

IDEA value for standard.

The IDEA values were then adjusted using this standardization factor: 
Table 3. In vitro digestibility (\%) of amino acids and CP in fish meal samples before (intact feed) and after (rumen residue) a 16-h ruminal in situ incubation determined via the modified 3-step procedure

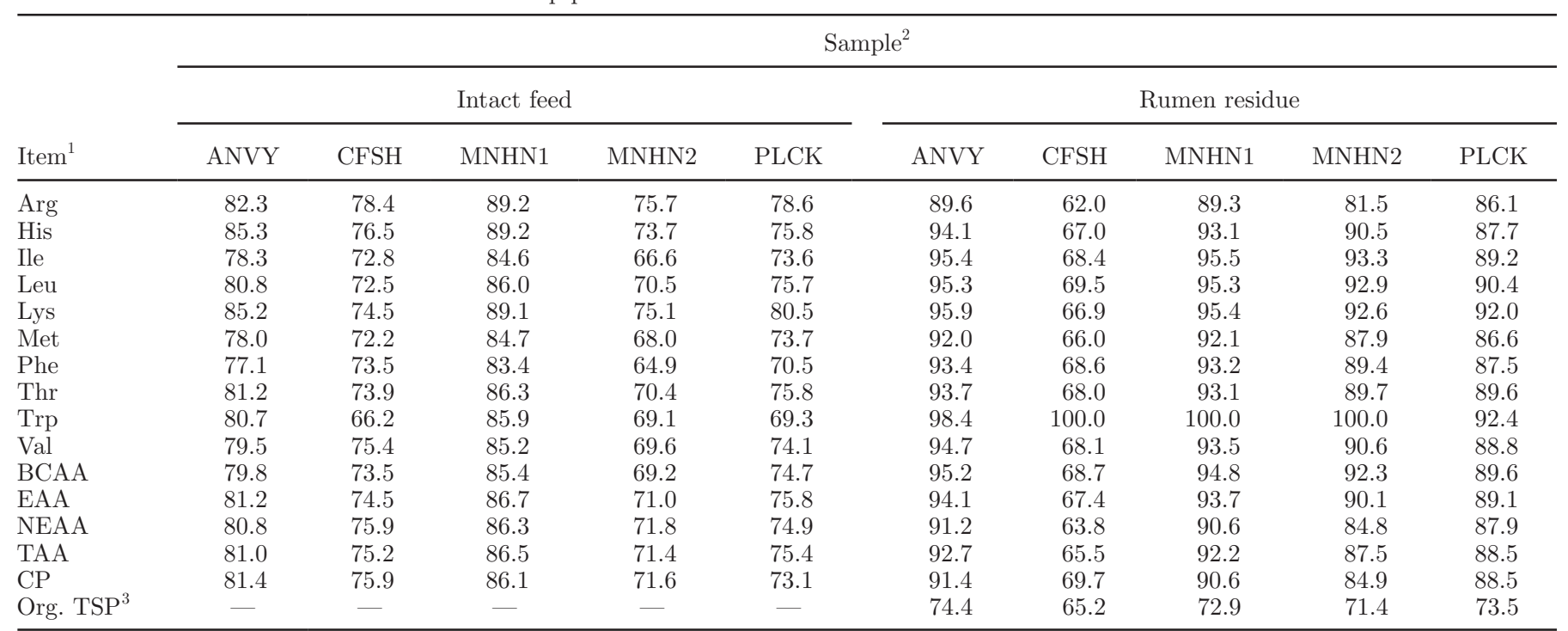

${ }^{1} \mathrm{BCAA}=$ branched chained $\mathrm{AA} ; \mathrm{EAA}=$ essential AA; NEAA = nonessential AA; TAA = total AA.

${ }^{2} \mathrm{ANVY}=$ anchovy fish meal; CFSH $=$ catfish meal; MNHN = menhaden fish meal; PLCK = pollock fish meal; numbers following samples indicate these samples are from different sources or batches.

${ }^{3}$ Rumen-undegradable protein digestibility determined via the original 3-step procedure of Calsamiglia and Stern (1995).

Corrected IDEA value $=$ IDEA value

$\times$ standardization factor.

For the SBM and FM kits, equations for calculating predicted AA digestibilities were also included. The equations were developed by Novus International Inc. based on regression analysis of IDEA values and standardized AA digestibility values determined in cecectomized roosters crop intubated with intact feed samples (Schasteen et al., 2007). Therefore, the equation for digestibility of each $\mathrm{AA}$ is $\mathrm{y}=\mathrm{mx}+\mathrm{b}$, but the values of $b$ and $m$ vary for each AA.

Using Lys as an example, the calculation is as follows:

SBM and SP: Predicted Lys digestibility $=$

$$
51.615+(46.270 \times \text { IDEA value }) \text {, and }
$$

FM: Predicted Lys digestibility $=66.404$

$$
+(78.681 \times \text { IDEA value }) .
$$

For the DDGS kits, digestibility of Lys is calculated in the same manner as for the other kits $(\mathrm{y}=\mathrm{mx}+\mathrm{b})$ :

DDGS: Predicted Lys digestibility $=$

$$
36.000+(34.029 \times \text { IDEA value }) \text {. }
$$

However, digestibility of Arg, Cys, Ile, Leu, Met, Thr, Trp, and Val is calculated based on predicted Lys digestibility. The calculation for the digestibility of these AA in DDGS is as follows, using Met as an example:

$$
\begin{gathered}
\text { Predicted Met digestibility }=69.870 \\
+(0.249 \times \text { IDEA-predicted Lys digestibility }) .
\end{gathered}
$$

Again, the values of $\mathrm{b}$ and $\mathrm{m}$ vary for each AA. Digestibility equations for all other AA are not provided with the DDGS kits.

\section{Statistical Analysis}

The REG procedure of SAS (SAS Institute, 2001) was used to examine the relationship between standardized AA and RUP-AA digestibility measured in vivo and digestibility determined using the modified TSP. In vivo digestibility was also compared with the IDEA values, digestibility calculated using the IDEA equations, and digestibility predicted by the IDEA values. The relationship between digestibility measurements obtained using the original TSP and modified TSP was also examined.

To determine if a mean or linear bias was present in the regression model for RUP-Lys digestibility determined via the modified TSP, the residuals (observed - predicted) were evaluated against predicted values (St-Pierre, 
Table 4. Coefficients of determination ( $\mathrm{R}^{2}$ values) between AA digestibility estimates obtained in cecectomized roosters and in vitro using the modified 3-step procedure for samples of soybean meal, SoyPlus, distillers dried grains with solubles, and fish meal

\begin{tabular}{|c|c|c|c|}
\hline \multirow[b]{2}{*}{ Item } & \multicolumn{3}{|c|}{$\mathrm{R}^{2}$} \\
\hline & $\begin{array}{l}\text { Residues in vitro } \\
\text { and in vivo } 1,2 \\
(\mathrm{n}=16)\end{array}$ & $\begin{array}{l}\text { Feeds in vitro } \\
\text { and in vivo }{ }^{1,3} \\
(\mathrm{n}=16)\end{array}$ & $\begin{array}{l}\text { Feeds in vitro } \\
\text { and residues in vivo } \\
\quad(\mathrm{n}=16)\end{array}$ \\
\hline $\operatorname{Arg}$ & 0.95 & 0.87 & 0.87 \\
\hline His & 0.86 & 0.80 & 0.76 \\
\hline Ile & 0.89 & 0.67 & 0.79 \\
\hline Leu & 0.89 & 0.68 & 0.74 \\
\hline Lys & 0.94 & 0.77 & 0.84 \\
\hline Met & 0.83 & 0.70 & 0.74 \\
\hline Phe & 0.89 & 0.69 & 0.76 \\
\hline Thr & 0.92 & 0.65 & 0.81 \\
\hline Trp & 0.85 & 0.25 & 0.22 \\
\hline Val & 0.91 & 0.71 & 0.81 \\
\hline Branched chained AA & 0.86 & 0.70 & 0.73 \\
\hline Essential AA & 0.92 & 0.73 & 0.80 \\
\hline Nonessential AA & 0.92 & 0.72 & 0.71 \\
\hline Total AA & 0.93 & 0.75 & 0.76 \\
\hline CP mod. ${ }^{5}$ & 0.90 & 0.74 & 0.74 \\
\hline $\mathrm{CP}$ org. ${ }^{6}$ & 0.71 & - & - \\
\hline CP org. vs. mod. ${ }^{7}$ & 0.86 & - & - \\
\hline \multicolumn{4}{|c|}{$\begin{array}{l}{ }^{1} \mathrm{R}^{2} \text { values in column significant }(P<0.01) \text { expect for Trp digestibility of the feeds in vitro and in vivo }(P= \\
0.06) \text { and Trp digestibility of feeds in vitro and residues in vivo }(P=0.08) \text {. }\end{array}$} \\
\hline \multicolumn{4}{|c|}{$\begin{array}{l}{ }^{2} \mathrm{R}^{2} \text { for AA digestibility of rumen-undegraded residues determined using the modified } 3 \text {-step procedure an } \\
\text { cecectomized roosters. }\end{array}$} \\
\hline \multicolumn{4}{|c|}{$\begin{array}{l}{ }^{3} \mathrm{R}^{2} \text { for AA digestibility of intact feeds determined using the modified } 3 \text {-step procedure and cecectomized roost } \\
\text { ers. }\end{array}$} \\
\hline \multicolumn{4}{|c|}{$\begin{array}{l}{ }^{4} \mathrm{R}^{2} \text { for AA digestibility of intact feeds determined using the modified } 3 \text {-step procedure and AA digestibility o } \\
\text { rumen-undegraded residues determined in cecectomized roosters. }\end{array}$} \\
\hline \multicolumn{4}{|c|}{$\begin{array}{l}{ }^{5} \mathrm{CP} \text { mod. }=\mathrm{CP} \text { digestibility determined via the modified } 3 \text {-step procedure compared with in vivo total } \mathrm{A} \\
\text { digestibility. }\end{array}$} \\
\hline \multicolumn{4}{|c|}{$\begin{array}{l}{ }^{6} \mathrm{CP} \text { org. }=\mathrm{CP} \text { digestibility determined via the original } 3 \text {-step procedure compared with in vivo total A } \\
\text { digestibility. }\end{array}$} \\
\hline $\begin{array}{l}{ }^{7} \mathrm{CP} \text { org. vs. mod. }= \\
\text { ibility determined via }\end{array}$ & 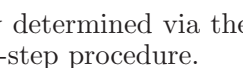 & & \\
\hline
\end{tabular}

2003) using the REG procedure of SAS (SAS Institute, 2001). Before regression analysis, the predicted values were centered at the mean predicted values for each model because this yields a more exact test for the mean bias (St-Pierre, 2003). To center the predicted values, the mean predicted value was subtracted from the individual predicted values. To determine equality of population correlations, correlation coefficients were transformed using Fisher's z-transformation, and the $P$-values were derived by treating the difference $\mathrm{z}_{1}-$ $\mathrm{z}_{2}$ as a normal random variable with mean zero and variance $1 /\left(n_{1}-3\right)+1 /\left(n_{2}-3\right)$, where $z_{1}$ and $z_{2}$ are Fisher's z-transformation of the correlations $r_{1}$ and $r_{2}$, respectively, and where $\mathrm{n}_{1}$ and $\mathrm{n}_{2}$ are the sample sizes.

\section{RESULTS AND DISCUSSION}

In vitro and in vivo digestibility estimates obtained for the RUR represent RUP-AA digestibility values. Therefore, throughout the results and discussion, RUP-
AA digestibility will refer to digestibility estimates of the RUR, and AA digestibility will refer to digestibility estimates of the intact feeds.

\section{Modified TSP}

Digestibility of AA and RUP-AA determined via the modified TSP using Ankom R150 bags (50- $\mu \mathrm{m}$ pore size) for soy-product (SP and SBM), DDGS, and FM samples are presented in Tables 1, 2, and 3, respectively. In vitro AA and RUP-AA digestibility estimates obtained with this procedure generally agree well with previously reported in vivo estimates for both the intact feeds and RUR (Boucher et al., 2009a,b). However, for the intact FM samples, in vitro estimates were substantially lower than previously reported in vivo estimates (Table 3; Boucher et al., 2009b). For example, average total AA digestibility values for intact FM samples were (mean \pm SD) $78 \pm 5$ and $87 \pm 5 \%$ in vitro and in vivo, respectively. This discrepancy may be because 

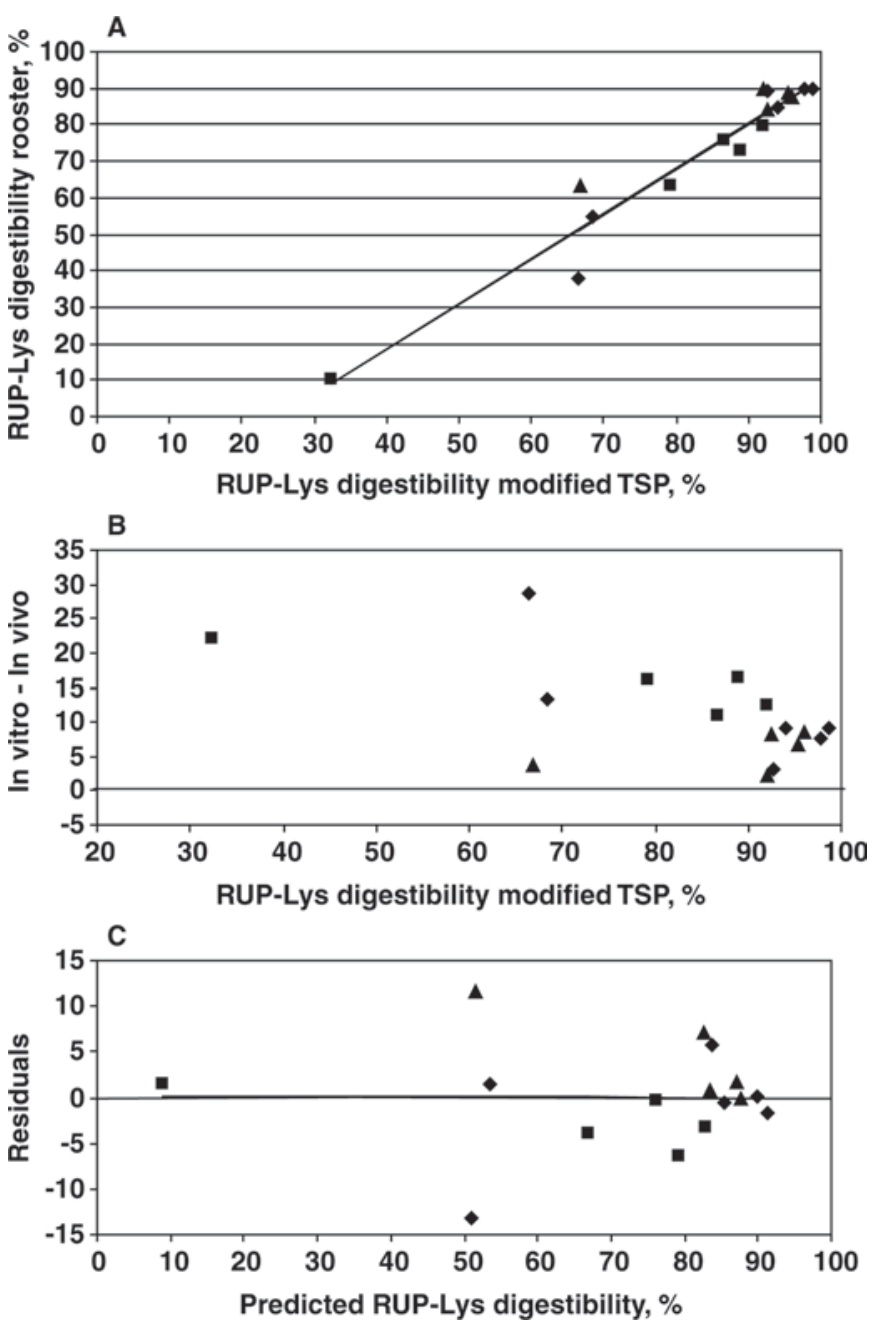

Figure 1. Regression plot of RUP-Lys digestibility of soy product $(\bullet ; \mathrm{n}=6)$, distillers dried grains with solubles $(\mathbf{\square} ; \mathrm{n}=5)$, and fish meal $(\boldsymbol{\Lambda} ; \mathrm{n}=5)$ rumen-undegraded residue samples determined via the modified 3-step procedure (TSP) and in cecectomized roosters. A) Y $=-31.37( \pm 7.30)+1.24( \pm 0.09) \mathrm{X}$; root mean square error (RMSE) $\left.=5.81 ; \mathrm{R}^{2}=0.94, P<0.0001, \mathrm{n}=16 ; \mathrm{B}\right)$ plot of in vitro estimates minus in vivo estimates; and $\mathrm{C}$ ) a plot of the residuals on the predicted values: $\mathrm{Y}=1.1 \mathrm{E}^{-18}( \pm 1.45)-3.67 \mathrm{E}^{-10}( \pm 0.07)(\mathrm{X}-72.60) ; \mathrm{RMSE}=$ $5.81 ; \mathrm{R}^{2}=0.00, P=1.00, \mathrm{n}=16$.

of the fat content of intact FM, which was higher than the fat content of FM RUR. Fat could clog the pores in the bags, which could decrease disappearance of AA from the bags.

Coefficients of determination between in vitro and in vivo AA and RUP-AA digestibility are presented in Table 4. In vitro digestibility estimates for all AA and RUP-AA were highly correlated to in vivo estimates. In addition, the relationship between in vitro AA digestibility and in vivo RUP-AA digestibility was examined (Table 4). In vitro AA digestibility was highly correlated to in vivo RUP-AA digestibility for all AA (Table $4 ; \mathrm{R}^{2}$ for total $\mathrm{AA}=0.76$ ). Equality of correlations was tested for the correlation between in vivo RUP-AA digestibility and in vitro AA digestibility of the intact feeds and in vivo RUP-AA digestibility and in vitro RUP-AA digestibility. The strength of correlation was equal for the correlation between in vivo RUP-AA digestibility and in vitro AA digestibility of the intact feeds and in vivo RUP-AA digestibility and in vitro RUP-AA digestibility $(P>0.05$; data not shown). Therefore, further investigation into estimating RUP-AA digestibility from in vitro digestibility of AA in the intact feedstuff is warranted because it could potentially eliminate the need to use live animals for any step in determining RUP-AA digestibility.

To our knowledge, this is the first study to validate the use of the modified TSP with in vivo data. Borucki-Castro et al. (2007) evaluated the use of the original TSP to estimate digestibility of RUP-AA in different SBM products and used GC-MS with a mass selective detector to quantify AA in the final supernatant. Estimates of RUP-AA digestibility obtained in vitro were compared with in situ digestibility estimates obtained using the mobile bag technique in lactating dairy cows with collection of bags from the feces. However, coefficients of determination between in situ and in vitro RUP-AA digestibility estimates were low. In the present experiment, digestibility of total RUP was also determined via the original TSP (Calsamiglia and Stern, 1995; Tables 1-3) and compared with digestibility of RUP-total AA estimated in cecectomized roosters (Table 4; accurate estimates of CP digestibility cannot be obtained in roosters because of mixing of urine and feces). The correlation between in vitro RUP digestibility and in vivo RUP-total AA digestibility was similar $(P>0.05$; data not shown) for the original TSP compared with the modified TSP.

In Vitro Lys Digestibility. The relationship between in vitro and in vivo RUP-Lys digestibility estimates is illustrated in Figure 1. In vitro RUP-Lys digestibility estimates were higher than in vivo estimates for all samples (Figure 1B). This discrepancy between in vitro and in vivo RUP-Lys digestibility estimates is likely because if the Maillard reaction has occurred, Lys can be present in feeds in forms that are not readily available for absorption in the small intestine (Mauron, 1990). Such Lys compounds could pass through the pores of the bags used in the modified TSP, resulting in inflated Lys digestibility estimates. Therefore, the use of Ankom F57 bags (25- $\mu$ m pore size) with the modified TSP was evaluated to determine if a bag with a smaller pore size could improve in vitro Lys digestibility estimates (data not shown). However, AA digestibility estimates obtained with the F57 bags were also substantially lower than in vivo estimates (data not shown). Gargallo et al. (2006) used both R150 and 
Table 5. Immobilized digestive enzyme assay (IDEA) values and essential AA digestibility (\%) values calculated using IDEA equations for samples of SoyPlus (SP; West Central Cooperative, Ralston, IA) and soybean meal (SBM) before (intact feed) and after 16-h ruminal incubation (rumen residue)

\begin{tabular}{|c|c|c|c|c|c|c|c|c|c|c|c|c|}
\hline Item & \multicolumn{12}{|c|}{ Sample $^{1}$} \\
\hline $\begin{array}{l}\text { IDEA value } \\
\text { AA digestibility, } \%\end{array}$ & 0.341 & 0.407 & 0.999 & 0.878 & 0.920 & 1.001 & 0.216 & 0.184 & 0.745 & 0.804 & 0.789 & 0.822 \\
\hline Arg & 74.0 & 76.6 & 99.7 & 95.0 & 96.6 & 99.8 & 69.1 & 67.9 & 89.8 & 92.1 & 91.5 & 92.8 \\
\hline Leu & 63.1 & 67.0 & 101.8 & 94.7 & 97.1 & 101.9 & 55.9 & 54.0 & 86.9 & 90.3 & 89.5 & 91.4 \\
\hline Lys & 67.4 & 70.4 & 97.8 & 92.3 & 94.2 & 97.9 & 61.6 & 60.2 & 86.1 & 88.8 & 88.1 & 89.7 \\
\hline Met & 59.4 & 63.8 & 103.1 & 95.1 & 97.8 & 103.2 & 51.2 & 49.1 & 86.3 & 90.1 & 89.2 & 91.3 \\
\hline Phe & 65.9 & 69.6 & 102.4 & 95.7 & 98.0 & 102.4 & 59.1 & 57.3 & 88.3 & 91.6 & 90.8 & 92.6 \\
\hline Thr & 62.9 & 66.6 & 99.6 & 92.9 & 95.2 & 99.7 & 56.0 & 54.2 & 85.5 & 88.7 & 87.9 & 89.7 \\
\hline Trp & 60.6 & 65.6 & 110.7 & 101.5 & 104.7 & 110.8 & 51.1 & 48.7 & 91.4 & 95.9 & 94.7 & 97.2 \\
\hline Val & 57.2 & 61.7 & 101.5 & 93.4 & 96.2 & 101.6 & 48.8 & 46.7 & 84.4 & 88.4 & 87.4 & 89.6 \\
\hline
\end{tabular}

${ }^{1} \mathrm{H}$ indicates the sample was heated at $150^{\circ} \mathrm{C}$ for $90 \mathrm{~min}$; numbers following samples indicate these samples are from different sources or batches. Heated samples were independent samples and do not correspond to another sample.

F57 bags in the development of the modified TSP and reported that although CP digestibility determined via the original and modified TSP was highly correlated for both bag types $\left(\mathrm{R}^{2}=0.98\right), \mathrm{CP}$ digestibility was lower when the F57 bags were used. Based on these results and the results of the present experiment, it is recommended that the Ankom R150 bags be used in the modified TSP.

As mentioned previously, although there was a high correlation between in vivo and in vitro RUP-Lys digestibility estimates (Figure 1A), the modified TSP overestimated RUP-Lys digestibility of all samples (Figure 1B). Therefore, to determine if a mean or linear bias was present in the regression model, the residuals (observed - predicted) were plotted against centered predicted RUP-Lys digestibility values (Figure 1C).
The mean predicted value used to center the data was $72.6 \%$. The mean bias and slope bias were nonsignificant for RUP-Lys digestibility. Therefore, it is concluded that the modified TSP procedure is an accurate procedure to estimate digestibility of RUP-Lys in SBM, SP, DDGS, and FM. Based on visual assessment of the regression plots, RUP-Lys digestibility determined via the modified TSP will not precisely predict RUP-Lys digestibility for every sample, but on average the modified TSP will yield an accurate estimate of RUP-Lys digestibility.

\section{IDEA}

The IDEA values and digestibility of AA and RUPAA calculated from the equations provided with the

Table 6. Immobilized digestive enzyme assay (IDEA) values and essential AA digestibility (\%) values calculated using IDEA equations for samples of distillers dried grains with solubles (DDGS) samples before (intact feed) and after 16-h ruminal incubation (rumen residue)

\begin{tabular}{|c|c|c|c|c|c|c|c|c|c|c|}
\hline \multirow{2}{*}{ Item } & \multicolumn{10}{|c|}{ Sample $^{1}$} \\
\hline & \multicolumn{5}{|c|}{ Intact feed } & \multicolumn{5}{|c|}{ Rumen residue } \\
\hline $\begin{array}{l}\text { IDEA value } \\
\text { AA digestibility, }{ }^{2} \%\end{array}$ & 0.494 & 1.012 & 1.105 & 1.070 & 0.895 & 0.243 & 0.422 & 0.462 & 0.416 & 0.460 \\
\hline Arg & 78.3 & 86.3 & 87.7 & 83.1 & 84.5 & 74.4 & 77.2 & 77.8 & 77.1 & 77.8 \\
\hline Lys & 52.8 & 70.4 & 73.6 & 63.4 & 66.5 & 44.3 & 50.4 & 51.7 & 50.1 & 51.7 \\
\hline Met & 83.0 & 87.4 & 88.2 & 85.7 & 86.4 & 80.9 & 82.4 & 82.8 & 82.4 & 82.7 \\
\hline Thr & 65.6 & 75.5 & 77.2 & 71.5 & 73.2 & 60.8 & 64.2 & 65.0 & 64.1 & 65.0 \\
\hline $\operatorname{Trp}$ & 71.4 & 84.3 & 86.6 & 79.1 & 81.4 & 65.2 & 69.6 & 70.6 & 69.5 & 70.6 \\
\hline
\end{tabular}

${ }^{1} \mathrm{H}$ indicates the sample was heated at $140^{\circ} \mathrm{C}$ for 60 min; numbers following samples indicate these samples are from different sources or batches. Heated samples were independent samples and do not correspond to another sample.

${ }^{2}$ Digestibility coefficients for His and Phe are not included in the IDEA DDGS kit. 
Table 7. Immobilized digestive enzyme assay (IDEA) values and essential AA digestibility (\%) values calculated using IDEA equations for fish meal samples before (intact feed) and after 16-h ruminal incubation (rumen residue)

\begin{tabular}{|c|c|c|c|c|c|c|c|c|c|c|}
\hline \multirow{2}{*}{ Item } & \multicolumn{10}{|c|}{ Sample $^{1}$} \\
\hline & \multicolumn{5}{|c|}{ Intact feed } & \multicolumn{5}{|c|}{ Rumen residue } \\
\hline $\begin{array}{l}\text { IDEA value } \\
\text { AA digestibility, \% }\end{array}$ & 0.260 & 0.119 & 0.288 & 0.300 & 0.261 & 0.074 & 0.032 & 0.086 & 0.100 & 0.170 \\
\hline Arg & 91.3 & 86.5 & 92.3 & 92.7 & 91.3 & 84.9 & 83.5 & 85.3 & 85.8 & 88.2 \\
\hline Leu & 91.9 & 84.1 & 93.4 & 94.1 & 91.9 & 81.6 & 79.3 & 82.3 & 83.0 & 86.9 \\
\hline Lys & 86.9 & 75.7 & 89.0 & 90.0 & 86.9 & 72.2 & 68.9 & 73.2 & 74.2 & 79.8 \\
\hline Met & 92.1 & 83.5 & 93.7 & 94.5 & 92.1 & 80.8 & 78.2 & 81.5 & 82.3 & 86.6 \\
\hline Phe & 90.9 & 83.4 & 92.3 & 93.0 & 90.9 & 81.0 & 78.8 & 81.7 & 82.4 & 86.1 \\
\hline Thr & 90.0 & 80.7 & 91.8 & 92.6 & 90.0 & 77.7 & 74.9 & 78.5 & 79.4 & 84.0 \\
\hline Trp & 96.0 & 89.0 & 97.4 & 98.0 & 96.0 & 86.7 & 84.6 & 87.3 & 88.0 & 91.5 \\
\hline Val & 90.9 & 82.5 & 92.5 & 93.3 & 90.9 & 79.8 & 77.3 & 80.5 & 81.3 & 85.5 \\
\hline
\end{tabular}

${ }^{1} \mathrm{ANVY}=$ anchovy fish meal; CFSH = catfish meal; MNHN = menhaden fish meal; PLCK = pollock fish meal; numbers following samples indicate these samples are from different sources or batches.

IDEA kits for soy products, DDGS, and FM samples are presented in Tables 5, 6, and 7, respectively. Only digestibility estimates of essential AA are presented. The $\mathrm{R}^{2}$ values between AA and RUP-AA digestibility calculated from the equations included with IDEA kits and in vivo measured AA and RUP-AA digestibility are presented in Table 8 . All relationships were highly correlated except for calculated and measured RUP-AA digestibility of the FM samples. However, there were large discrepancies between calculated and measured RUP-Lys and RUP-Met digestibility values for all samples (Figure 2). Therefore, if the IDEA kits are to be used to estimate RUP-AA digestibility, new prediction equations that are specific for RUP-AA digestibility should be developed.
To develop such equations, the IDEA values of the RUR were regressed on in vivo RUP-AA digestibility. The IDEA values of the RUR were highly correlated with in vivo RUP-AA digestibility of the soy-product and DDGS samples, but for the FM samples, the IDEA values were not highly correlated with RUP-AA digestibility (Table 9). However, because the IDEA values are used to predict, not measure, AA digestibility, the relationship between the IDEA value of the intact feed and RUP-AA digestibility measured in vivo was also examined to determine if the IDEA value of the feed could be used to predict RUP-AA digestibility. Results of this analysis are presented in Table 9. Equality of correlations was also tested for the correlation between in vivo RUP-AA digestibility and the IDEA values of

Table 8. Coefficients of determination ( $\mathrm{R}^{2}$ values) between essential AA digestibility calculated using immobilized digestive enzyme assay (IDEA) equations and measured in cecectomized roosters crop intubated with SoyPlus (SP; West Central Cooperative, Ralston, IA), soybean meal (SBM), distillers dried grains with solubles (DDGS), and fish meal (FM) samples before (intact feeds) and after (rumen residue) 16-h ruminal incubation

\begin{tabular}{|c|c|c|c|c|c|c|}
\hline \multirow{2}{*}{ AA } & \multicolumn{6}{|c|}{$\mathrm{R}^{2}$ for digestibility by IDEA equations and standardized digestibility in roosters } \\
\hline & \multicolumn{3}{|c|}{ Intact feed } & \multicolumn{3}{|c|}{ Rumen residue } \\
\hline Arg & 0.79 & 0.79 & 0.99 & 0.77 & 0.95 & 0.34 \\
\hline His & 0.85 & - & 0.81 & 0.82 & - & 0.52 \\
\hline Lys & 0.92 & 0.84 & 0.73 & 0.91 & 0.94 & 0.53 \\
\hline Met & 0.87 & 0.80 & 0.92 & 0.83 & 0.95 & 0.46 \\
\hline Phe & 0.82 & - & 0.87 & 0.77 & - & 0.48 \\
\hline Thr & 0.86 & 0.81 & 0.91 & 0.83 & 0.96 & 0.49 \\
\hline Trp & 0.87 & 0.88 & 0.94 & 0.84 & 0.78 & 0.59 \\
\hline Val & 0.83 & 0.81 & 0.85 & 0.82 & 0.94 & 0.47 \\
\hline
\end{tabular}



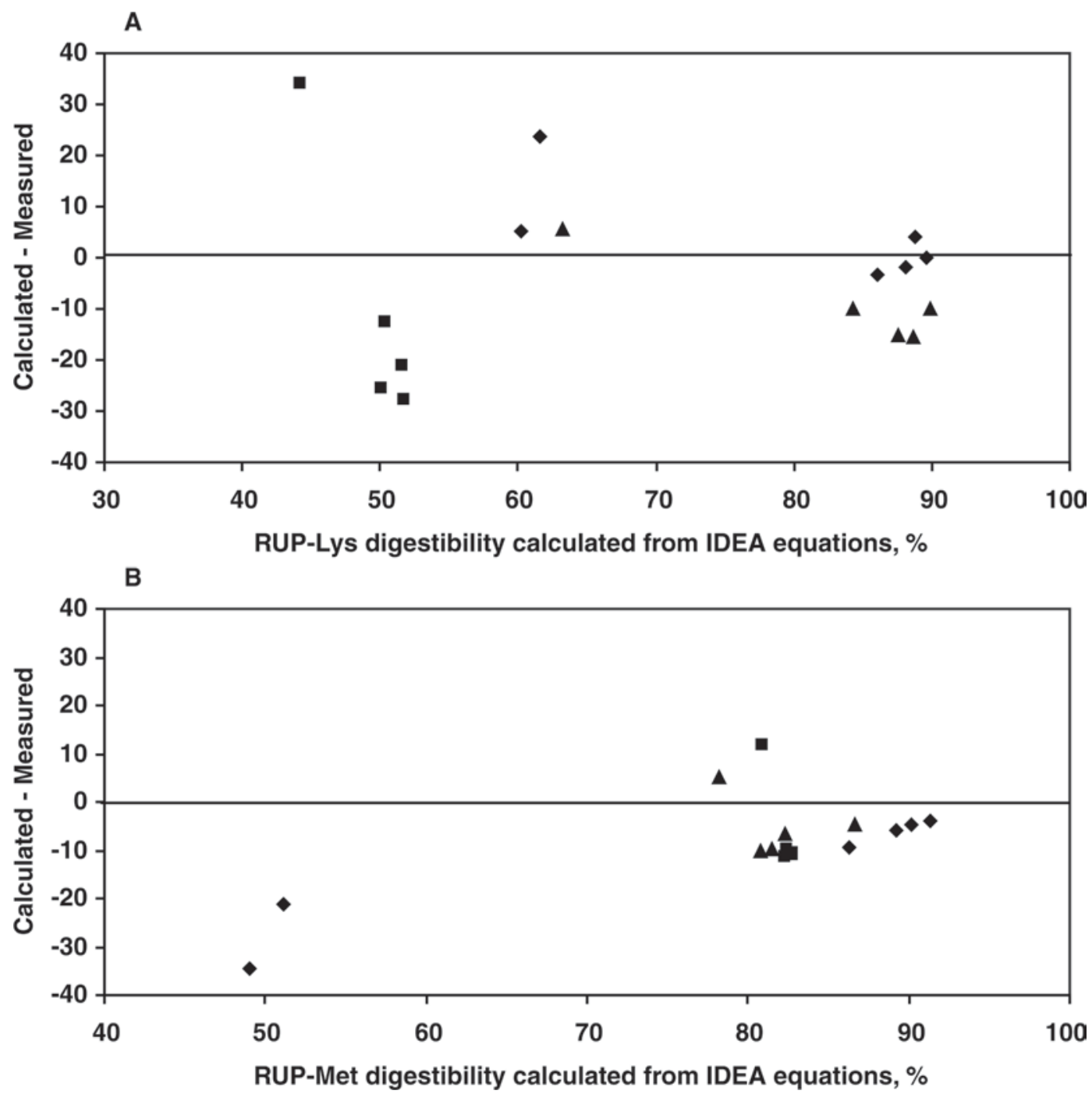

Figure 2. Plots of A) RUP-Lys and B) RUP-Met digestibility calculated from immobilized digestive enzyme assay (IDEA) equations minus RUP-Lys and Met digestibility measured in vivo for samples of soy products $(\bullet ; n=6)$, distillers dried grains with solubles $(\mathbf{\square} ; n=5)$, and fish meal $(\boldsymbol{\Lambda} ; \mathrm{n}=5)$.

the RUR and intact feeds. The strength of correlation was equal for the correlation between the IDEA value of the intact samples and in vivo RUP-AA digestibility and the correlation between the IDEA value of the RUR samples and in vivo RUP-AA digestibility for all feedstuffs $(P>0.05$; data not shown). Therefore, for a more efficient, cost-effective analysis, it is recommended that for future IDEA analysis, the IDEA values of the intact samples be determined and the IDEA value of the intact feed be compared with in vivo RUP-AA digestibility to develop accurate prediction equations.

In the development of the IDEA kits, only results from the SBM IDEA kit have been published (Schasteen et al., 2007). Schasteen et al. (2007) reported that the IDEA value of SBM samples was highly correlated to standardized AA digestibility determined in vivo for all $\mathrm{AA}$. In their analysis, $\mathrm{R}^{2}$ values ranged from 0.73 for Cys to 0.91 for Asp, and the $\mathrm{R}^{2}$ values for Lys and Met were 0.86 and 0.88 , respectively. The IDEA values ranged from 0.44 to 0.90 , which corresponded to in vivo Lys digestibility estimates of 71 and $92 \%$, and in vivo Met digestibility estimates of 64 and $95 \%$, respectively. In the present experiment the IDEA values of the intact soy-product samples ranged from 0.34 to 1.0 (Table 5), which corresponded to in vivo Lys digestibility estimates of 67 and $98 \%$ and Met digestibility estimates of 59 and 103\%, respectively (Boucher et al., 2009a). The lowest SBM Lys digestibility estimate reported by Schasteen et al. (2007) was $71 \%$, so the accuracy of the kit below $70 \%$ digestibility was unknown. In the present 
Table 9. Coefficients of determination ( $\mathrm{R}^{2}$ values) between immobilized digestive enzyme assay (IDEA) values of rumen residues and intact feeds and standardized RUP-AA ${ }^{1}$ digestibility in cecectomized roosters crop intubated with samples of SoyPlus (SP; West Central Cooperative, Ralston, IA), soybean meal (SBM), distillers dried grains with solubles (DDGS), and fish meal (FM)

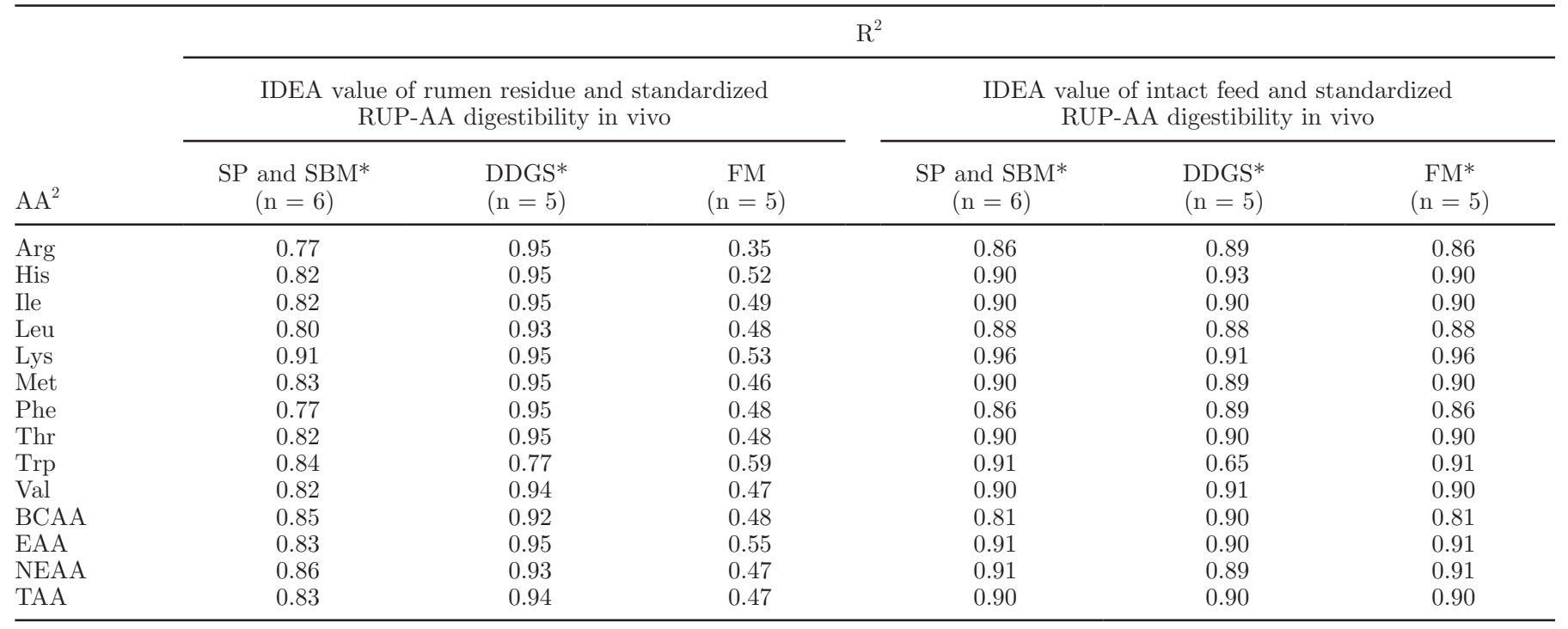

${ }^{1} \mathrm{RUP}-\mathrm{AA}=$ amino acids in rumen-undegraded protein.

${ }^{2} \mathrm{BCAA}=$ branched chained $\mathrm{AA} ; \mathrm{EAA}=$ essential $\mathrm{AA} ; \mathrm{NEAA}=$ nonessential $\mathrm{AA} ; \mathrm{TAA}=$ total AA.

*All values in column significant, $P<0.01$.

experiment, in vivo RUP-Lys digestibility values as low as $38 \%$ were observed for the soy-product samples, and even with Lys digestibility below the reported range, the correlation between in vivo Lys digestibility and IDEA values was high, which suggests that the IDEA kits may be useful for estimating AA digestibility of poorly digested samples.

\section{CONCLUSIONS}

The modified TSP and IDEA assays appear to be adequate techniques for estimating RUP-AA digestibility in SP, SBM, DDGS, and FM. However, there are benefits and drawbacks to both methods. The modified TSP can be used to estimate RUP-AA digestibility of any feedstuff, and the analysis can be performed by any lab. However, the final undigested residue obtained from the modified TSP needs to be analyzed for AA content, which increases the time needed to obtain digestibility estimates and the cost of analysis. The IDEA kit assays are specific to each feed type, which limits the use of the kits. The kits can currently be purchased through Novus International Inc., but the kits only include equations for estimating AA digestibility of feedstuffs in poultry. Further development of the kits for use in ruminant species is needed. However, the kit techniques are rapid and there is no need for AA analysis after the IDEA assay is performed. For both the modified TSP and the IDEA kit assay, in vitro AA digestibility estimates of the intact feeds were highly correlated to in vivo RUP-AA digestibility; therefore, future analysis of these methods should focus on predicting RUP-AA digestibility from in vitro analysis of AA digestibility of the intact feed. It will be faster and more cost effective if the intact feeds can be used to provide accurate predictions of RUP-AA digestibility.

\section{ACKNOWLEDGMENTS}

The authors thank West Central (Ralston, IA), Adisseo (Alpharetta, GA), and Novus International Inc. (St. Louis, MO) for financial support of this project. Gratitude is also extended to Melissa Thrune (University of Minnesota, St. Paul) for help with the 3-step procedure, and Jennifer Wu (Novus International, St. Louis, MO) for help with the IDEA assays.

\section{REFERENCES}

AOAC. 1980. Official Methods of Analysis. 13th ed. AOAC, Washington, DC.

AOAC. 2000. Official Methods of Analysis. Vol. 1 and 2. 17th ed. AOAC Int., Gaithersburg, MD.

Borucki-Castro, S. I., L. E. Phillip, H. Lapierre, P. W. Jardon, and R. Berthiaume. 2007. Ruminal degradability and intestinal digestibility of protein and amino acids in treated soybean meal products. J. Dairy Sci. 90:810-822.

Boucher, S. E., S. Calsamiglia, C. M. Parsons, H. H. Stein, M. D. Stern, P. S. Erickson, P. L. Utterback, and C. G. Schwab. 2009a Intestinal digestibility of amino acids in rumen undegraded protein: I. Soybean meal and SoyPlus. J. Dairy Sci. Accepted. doi:10.3168/jds.2008-1884 
Boucher, S. E., S. Calsamiglia, C. M. Parsons, H. H. Stein, M. D. Stern, P. S. Erickson, P. L. Utterback, and C. G. Schwab. 2009b. Intestinal digestibility of amino acids in rumen undegraded protein: II. Distillers dried grains with solubles and fish meal. J. Dairy Sci. Submitted. doi:10.3168/jds.2008-1885

Calsamiglia, S., and M. D. Stern. 1995. A three-step in vitro procedure for estimating intestinal digestion of protein in ruminants. J Anim. Sci. 73:1459-1465.

Church, F. C., H. E. Swaisgood, and G. L. Catignani. 1984 Compositional analysis of proteins following hydrolysis by immobilized proteases. J. Appl. Biochem. 6:205-211.

Gargallo, S., S. Calsamiglia, and A. Ferret. 2006. Technical note: A modified three-step in vitro procedure to determine intestinal digestion of proteins. J. Anim. Sci. 84:2163-2167.

Mauron, J. 1990. Influence of processing on protein quality. J. Nutr. Sci. Vitaminol. (Tokyo) 36:S57-S69

NRC. 2001. Nutrient Requirements of Dairy Cattle. 7th rev. ed. Natl Acad. Sci. Washington D.C.
Novus International. 2008. IDEA. Poultry. http://www.novusint.com/ species/poultry/products.aspx?product=idea Accessed April 1, 2008.

SAS Institute. 2001. SAS/STAT User's Guide. Version 8 ed. SAS Institute Inc., Cary, NC

Schasteen, C. S., J. Wu, M. G. Schulz, and C. M. Parsons. 2007. Correlation of an immobilized digestive enzyme assay with poultry true amino acid digestibility for soybean meal. Poult. Sci. 86:343348.

St-Pierre, N. R. 2003. Reassessment of biases in predicted nitrogen flows to the duodenum by NRC 2001. J. Dairy Sci. 86:344-350.

Titgemeyer, E., N. Merchen, Y. Han, C. Parsons, and D. Baker. 1990. Assessment of intestinal amino acid availability in cattle by use of the precision-fed cecectomized rooster assay. J. Dairy Sci. 73:690-693 